\title{
Changes in ice-shelf buttressing following the collapse of Larsen A Ice Shelf, Antarctica, and the resulting impact on tributaries
}

\author{
SAM ROYSTON, * G. HILMAR GUDMUNDSSON \\ British Antarctic Survey, Cambridge, UK \\ Correspondence: Sam Royston <sam.royston@utas.edu.au>
}

\begin{abstract}
The dominant mass-loss process on the Antarctic Peninsula has been ice-shelf collapse, including the Larsen A Ice Shelf in early 1995. Following this collapse, there was rapid speed up and thinning of its tributary glaciers. We model the impact of this ice-shelf collapse on upstream tributaries, and compare with observations using new datasets of surface velocity and ice thickness. Using a two-horizontal-dimension shallow shelf approximation model, we are able to replicate the observed large increase in surface velocity that occurred within Drygalski Glacier, Antarctic Peninsula. The model results show an instantaneous twofold increase in flux across the grounding line, caused solely from the reduction in backstress through ice shelf removal. This demonstrates the importance of ice-shelf buttressing for flow upstream of the grounding line and highlights the need to explicitly include lateral stresses when modelling real-world settings. We hypothesise that further increases in velocity and flux observed since the ice-shelf collapse result from transient mass redistribution effects. Reproducing these effects poses the next, more stringent test of glacier and ice-sheet modelling studies.
\end{abstract}

KEYWORDS: buttressing, glacier modelling, ice shelves

\section{INTRODUCTION}

The Larsen Ice Shelf, located to the east of the Antarctic Peninsula, has exhibited a persistent, stepped retreat since aerial observations began in the 1950s, with significant retreat since 1986 (Fig. 1; Cooper, 1997; Ferrigno and others, 2008; Cook and Vaughan, 2010). Between January and March 1995, the majority of the Larsen A Ice Shelf collapsed, co-incident with the collapse of the Prince Gustav Ice Shelf and a large calving event from the Larsen B Ice Shelf (Rott and others, 1996). The floating area of the Larsen A Ice Shelf reduced by half during the last week of January 1995 alone, and by 8 March 1995, covered only $18 \%$ of its previous extent (Rott and others, 1997; Skvarca and others, 1999). At the time of collapse, there was considerable debate regarding the role of lateral buttressing in flow dynamics, specifically the nature of grounding line dynamics following a significant perturbation such as the loss of an ice shelf (e.g. Weertman, 1974; Hindmarsh, 1993; Hindmarsh and Le Meur, 2001; Ritz and others, 2001; Dupont and Alley, 2005). Observations following the Larsen A collapse confirmed the significant and rapid effect of this event on the flow dynamics of tributary glaciers, with far-reaching effects upstream (Rott and others, 2002, 2014; De Angelis and Skvarca, 2003; Shuman and others, 2011). Previous modelling studies of Larsen A considered the conditions and possible mechanisms for the break-up of the ice shelf (Doake and others, 1998; Scambos and others, 2000; Vieli and others, 2007; Albrecht and Levermann, 2014), but did not consider the whole ice-sheet ice-shelf system including observed changes in buttressing and velocity and the effects upstream of the grounding line within tributary glaciers. The collapse of Larsen A provides one of the few examples in glaciology, where model validation can be performed.

* Present address: Surveying and Spatial Science, University of Tasmania, Private Bag 76, Hobart TAS 7001, Australia.
Surface velocities of Larsen A tributary glaciers upstream of the grounding line increased significantly within 8 months of the collapse, from $200 \mathrm{~m} \mathrm{a}^{-1}$ at the outlets of Drygalski and Dinsmoor-Bombardier-Edgeworth (DBE) glaciers to over $900 \mathrm{~m} \mathrm{a}^{-1}$ by austral spring 1995 (Fig. 2; Bindschadler and others, 1994; Rack and others, 1999; Rott and others, 2014; Seehaus and others, 2015) and continued accelerating for at least 5 a post collapse (Rott and others, 2014). This acceleration resulted in dynamic thinning and mass loss: in total, the mass loss from former Larsen A tributaries has contributed $17-18 \%$ of the mass loss from the northern Antarctic Peninsula (Scambos and others, 2014).

Recent reanalysed velocity datasets (Rott and others, 2014; Seehaus and others, 2015) and new developments in inversions for bed elevation (Huss and Farinotti, 2014) now enable high-resolution modelling of the former Larsen A Ice Shelf region including an investigation of the effects of a reduction in ice-shelf buttressing. Here, we use a numerical ice flow model of a type commonly used in glaciology to quantify future changes in flow due to changes following collapse in January 1995. We then compare these numerical results with remote-sensing observations of velocity obtained shortly after the collapse. Besides providing new insights into the effect of the ice-shelf collapse on ice-shelf buttressing, we are thereby able to test the performance of the numerical model against observations.

This paper demonstrates with a real-world example, the instantaneous effect that removing buttressing has on upsteam flow. Section 2 describes the numerical model and datasets used. We demonstrate that the observed glacier velocity speed up near the grounding line can be replicated well by modelling only the change in the ice shelf extent (Section 3). We discuss the modelled change in backstress due to the ice-shelf collapse, its effect on the acceleration of tributary glaciers in the vicinity of the grounding line and discrepancies between the modelled and observed 


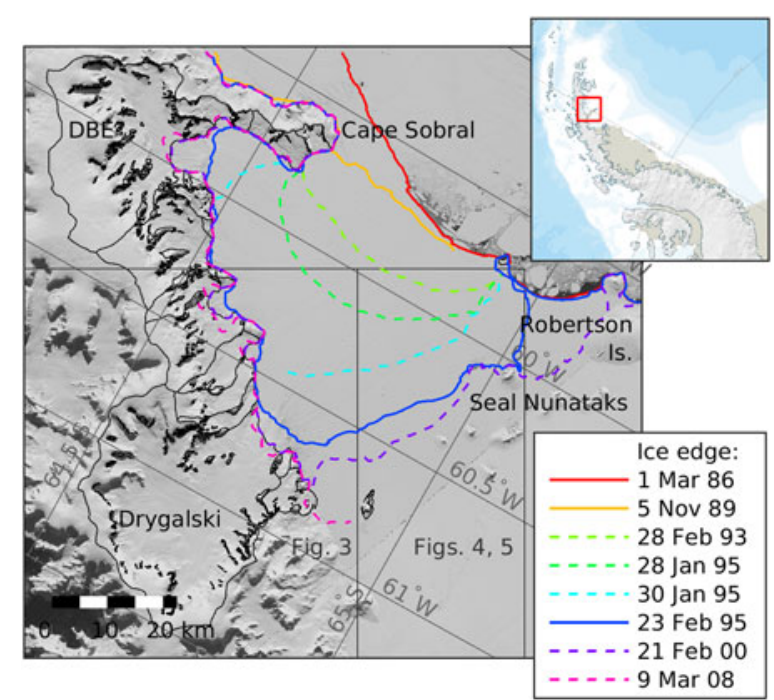

Fig. 1. Area of interest showing ice shelf extents (solid and dashed coloured lines; Skvarca and others, 1999; Ferrigno and others, 2008) and ice catchments (thin black lines; Cook and others, 2014). Inset displays the location on the Antarctic Peninsula using a basemap from the SCAR Antarctic Digital Database 6.0. Base image is Landsat from 1 Mar 1986. Figures are plotted using WGS84 Antarctic Polar Stereographic projection with Standard Parallel at $-71^{\circ} \mathrm{S}$.

data (Section 4). These discrepancies are discussed in the context of model limitations, transient effects and alternative contributing mechanisms on glacier acceleration of the order of $10 \mathrm{~km}$ upstream.

\section{METHODOLOGY}

We use an ice flow model to calculate the instantaneous changes in flow due to the collapse of Larsen A Ice Shelf. Ice flow, as calculated by the model, is primarily a function of geometry and model parameters describing basal sliding (slipperiness, C) and internal ice deformation (rate factor, $A$ ). These two distributed parameter sets were determined from measurements of ice flow using inversion techniques.

\subsection{Numerical model}

The numerical ice flow model, referred to as Úa, solves the shallow shelf approximation (SSA) equations in two-horizontal-dimensions (2HD) on a finite-element mesh. Úa has been tried-and-tested in all recent model intercomparison exercises (Pattyn and others, 2012, 2013) and in real world settings (Favier and others, 2014; De Rydt and others, 2015), and is described by Gudmundsson and others (2012).

The computational domain was discretised using linear, quadratic and cubic elements with sizes ranging from 100 to $1000 \mathrm{~m}$, with the finest resolution applied around grounding lines.

The model parameters basal slipperiness and rate factor were determined using commonly used inversion methods (MacAyeal, 1992, 1993), each with nonlinear exponents, $m=3$ and $n=3$.

\subsection{Model geometry}

We used the ice edge extents determined by Ferrigno and others (2008) for periods from March 1986 to February 1995 to define the model geometries prior and post collapse
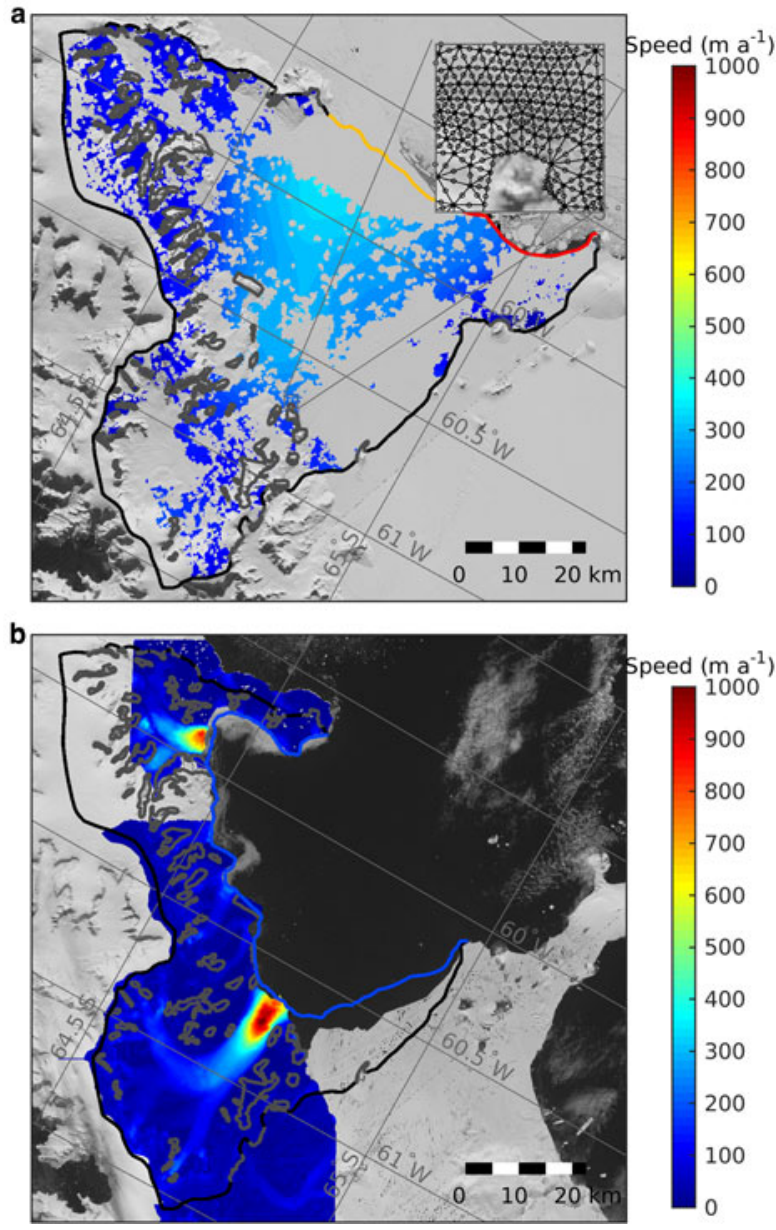

Fig. 2. Observed surface speeds from ERS-1 DInSAR pairs and model mesh extents (a) acquired 8 December 1992-16 February 1993 (Seehaus and others, 2015) with inset displaying the 6-node mesh and (b) acquired 31 October - 5 November 1995 (Rott and others, 2014). The model no-flow boundaries (thick black line), free-slip boundaries (thick grey line) and open boundaries (thick coloured lines, with colours relating to Fig. 1 for before and after the ice-shelf collapse respectively) are shown. Base images are Landsat, from 1 March 1986 and 31 December 2001, the latter acquired some time after the ice-shelf collapse.

(Figs 1, 2; data sources are listed in Table 1). Along the calving fronts the (vertically integrated) hydrostatic ocean pressure was applied. Along the furthermost upstream boundaries, velocities were set to zero. The model domain included several nunataks (SCAR Antarctic Digital Database 6.0 http://www.add.scar.org), and these ice-free regions were represented as holes in the finite-element mesh. Along such inner boundaries, a free-slip boundary condition was applied, where normal velocities were set to zero while the ice was allowed to move freely in tangential direction.

For the Antarctic Peninsula, surface topographic data at $100 \mathrm{~m}$ resolution has recently been published revisiting ASTER data (Cook and others, 2012). Unfortunately, the ASTER GDEM is derived from data acquired during the period 2000-09 but the acquisition date(s) used for each region have not been retained with the DEM and the data masked to the 2008 ice edge. Significant elevation changes have occurred since the ice-shelf collapse in 1995 and there appear to be several inconsistencies in the ASTER dataset between elevation and grounding line positions. 
Table 1. Data sources

\begin{tabular}{lll}
\hline Data & Source & Date of acquisition \\
\hline $\begin{array}{ll}\text { Ice edge before collapse } \\
\text { Ice edge after collapse }\end{array}$ & Ferrigno and others (2008) & 1 Mar 1986, 5 Nov 1989 \\
Grounded ice-surface elevation & Ferrigno and others (2008) & 23 Feb 1995 \\
$\begin{array}{l}\text { Floating ice-surface elevation } \\
\text { Bedrock elevation }\end{array}$ & REMP (Liu and others, 2001) & 1940-1999 \\
$\begin{array}{ll}\text { Bathymetry } \\
\text { Velocity before collapse }\end{array}$ & Huss and Farinotti (2014) & All valid data from 1992-1994 \\
Velocity after collapse & IBCSO (Arndt and others, 2013) & All available data \\
& Seehaus and others (2015) & All available data \\
\hline
\end{tabular}

Surface elevation required for hydrostatic equilibrium at the grounding line at Drygalski Glacier (from February 1996; Rignot and others, 2011) is $100 \mathrm{~m}$ above the ASTER GDEM surface elevation.

Having considered, and discounted, various possible modifications to the ASTER GDEM to arrive at a realistic elevation distribution around observe grounding lines, we instead used RAMP ice-surface data (an integration of elevation data acquired to 1999; Liu and others, 2001) in the region of grounded ice, supplemented by ERS-1 reanalysed altimetry data for the ice-shelf region (Gilbert and others, 2014). The ERS-1 altimetry was corrected for the geoid to make consistent with the surface and bedrock data, and for the tide using the CATS model v2.01 (Padman and others, 2002).

Bedrock data recently calculated by Huss and Farinotti (2014) at a high-horizontal resolution of $100 \mathrm{~m}$ was tied in to bathymetry from IBCSO (Arndt and others, 2013). Ice thickness was determined from the difference between the surface and bedrock data, with areas of floatation and hence the ice-shelf base determined from hydrostatic equilibrium arguments. In the floatation point calculation, the density of ice was estimated allowing for firn thickness and density determined by Ligtenberg and others (2011). The surface elevation, bathymetry and ice thickness was checked for consistency with the observed location of the grounding line before the ice-shelf collapse and from this assessment, we concentrate on the results for Drygalski Glacier.

\subsection{Surface velocities}

We used surface velocity datasets obtained from differential interferometry both prior and post collapse. The pre-collapse velocities were determined by Seehaus and others (2015) from pairs acquired between 8 December 1992 and 16 February 1993 and the post-collapse velocities were determined by Rott and others (2014) from pairs acquired between 31 October 1995 and 5 November 1995 (Fig. 2).

\section{RESULTS}

\subsection{Replicating post-collapse velocities}

Following the model inversion routine for the post-collapse state that initialised the model parameters for the grounded ice, model discrepancies were mostly small compared with the observed surface velocities (Fig. 3). The mean difference between modelled and observed speed across the whole domain is $-42.6 \mathrm{~m} \mathrm{a}^{-1}$ and the RMSE is $85.3 \mathrm{~m} \mathrm{a}^{-1}$. (The mean observed post-collapse speed across the domain is $86.1 \mathrm{~m} \mathrm{a}^{-1}$.)

The biggest discrepancy of $40 \%$ between modelled and observed velocities was found upstream of the right-hand flank of the glacier adjacent to Sentinel Nunatak. The observed post-collapse velocity (Fig. 2b) peaked here at over $1000 \mathrm{~m} \mathrm{a}^{-1}$ whereas the model predicted speeds around $600 \mathrm{~m} \mathrm{a}^{-1}$. However, along the grounding line and calving-front of Drygalski Glacier the modelled speeds were very close to those observed (Fig. 3b), which gives confidence in model estimates of the flux from grounded ice to floating or calved ice contributing to sea level.

\subsection{Change in the velocity field due to loss of ice-shelf buttressing}

After the above described initialisation step, the model was re-run with the section of the ice shelf that collapsed in

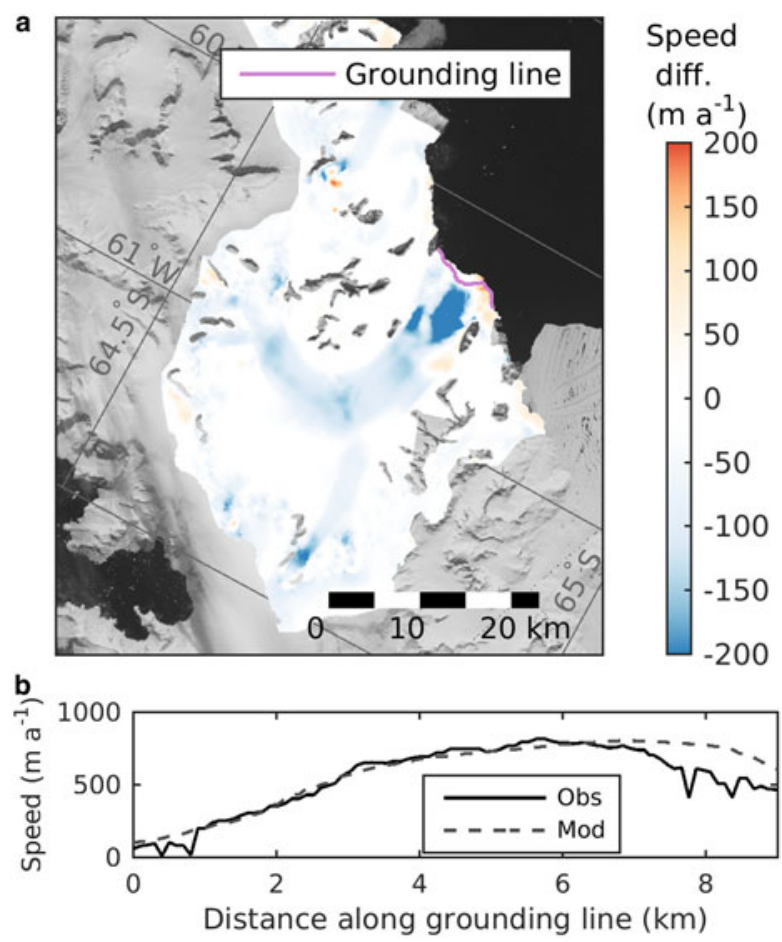

Fig. 3. Model initialisation: The difference between the modelled and observed surface speed $\left(\mathrm{m} \mathrm{a}^{-1}\right)$ for Drygalski Glacier following the ice-shelf collapse, after running the model inversion routine (a) in plan view and (b) along the grounding line and calving-front defined from DInSAR acquired in February 1996 (Rignot and others, 2011). 
January-March 1995 removed. The observed speed up of Drygalski Glacier between periods before and after the iceshelf collapse (Fig. 4a) was used to validate the modelled difference in speed (Fig. 4b).

The maximum modelled increase in speed of $722 \mathrm{~m} \mathrm{a}^{-1}$ compared well against the observed increase in speed of $763 \mathrm{~m} \mathrm{a}^{-1}$. However, the spatial distribution of the speed up was not fully replicated by the model, with the modelled impact of the collapse not affecting the ice flow as far upstream as observed. As discussed below, this discrepancy is most likely due to dynamic effects because the model results present the instantaneous impact of the ice-shelf collapse on ice velocities and the post-collapse velocity data from late 1995, 8 months after the collapse took place.

\section{DISCUSSION}

\subsection{Change in backstress due to ice-shelf collapse}

There has been a recent impetus in the discussion of ice stream dynamics and marine ice-sheet stability in regard to the effect of buttressing (Goldberg and others, 2009; Katz and Worster, 2010; Gudmundsson, 2013; Favier and others, 2014). A metric of local buttressing attributable to the presence of the ice shelf is defined by Gudmundsson (2013), calculated as the difference between the pressure, which would be exerted by hydrostatic equilibrium and that pressure acting normal to the grounding line. Positive values of this backstress metric define areas where the hydrostatic pressure equivalent from the presence of an ice shelf is greater than the englacial stresses acting against the direction of the grounding line (or flow field) and negative backstress indicates areas where the englacial stresses along the grounding line are greater than the hydrostatic pressure at that point.

Along the outflow of Drygalski Glacier and at a number of other outflows along the Cape Worsley coast, the modelled backstress decreases consistently (up to $-300 \mathrm{kPa}$ ) as a result of removing the ice shelf in the model (Fig. 5). Regions of a positive change in backstress are modelled where the ice shelf had flowed away from the grounding line 'pulling' the grounded ice out with it but after the iceshelf collapse the ice flow was stagnant (the backstress increased from negative to zero). It is noted that the Seal Nunataks remnant ice shelf is modelled to slow down after the ice-shelf collapse (Fig. 4). The slow down in surface velocity can be explained by a change in the primary direction of flow between the cases with and without the ice shelf present. With the Larsen A Ice Shelf present, the outflow from Drygalski Glacier progresses outwards towards the ice shelf edge pulling adjacent regions of ice shelf with it. After the 1995 break-up the Seal Nunataks remnant ice shelf becomes static, and the area modelled to slow down calved or disintegrated within 6 a (Fig. 4; the background image is taken from December 2001 and demonstrates further ice-shelf collapse). The backstress exerted within the remnant ice shelf is in the main reduced following the 1995 break-up of the main ice shelf (Fig. 5). The exceptions are in the vicinity of pinning points where the stress field remains unchanged, and closer to the grounding line where parts of the remnant ice shelf exhibit a modelled increase in backstress because the englacial stresses are no longer affected by the inflow from Drygalski Glacier and instead are primarily forced by hydrostatic pressure.
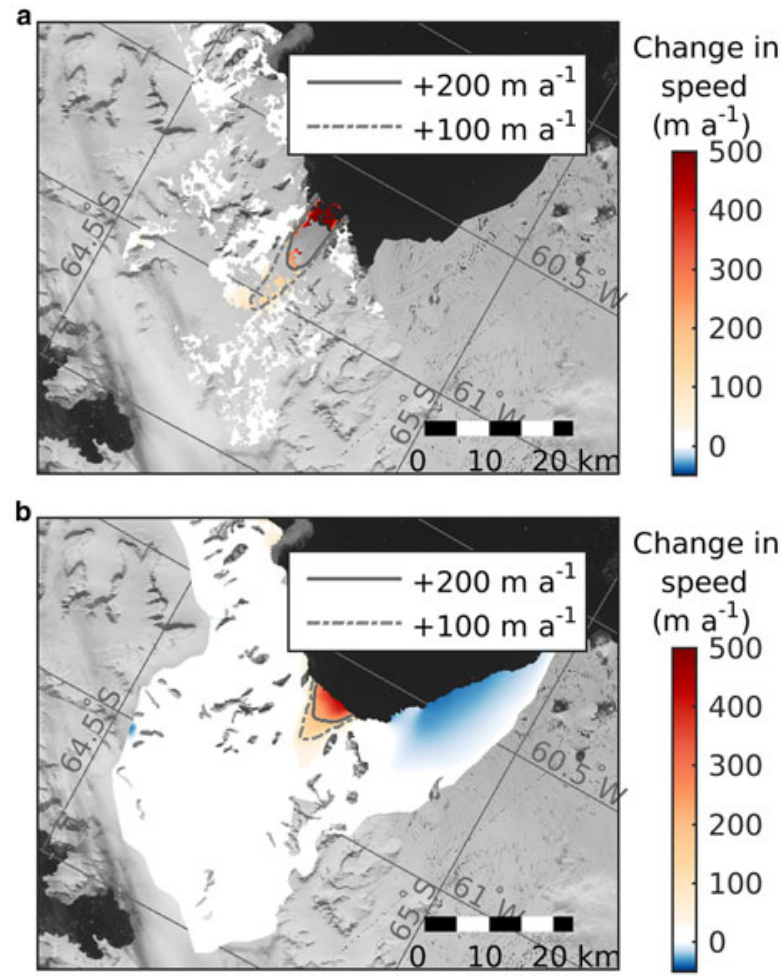

Fig. 4. The increase in speed $\left(\mathrm{m} \mathrm{a}^{-1}\right)$ for Drygalski Glacier as a result of the collapse of Larsen A Ice Shelf (a) from observations (see Fig. 2) and (b) modelled by removing the ice-shelf geometry (from the 1989 extent to the 1995 extent). Note that the colour scale is saturated at $500 \mathrm{~m} \mathrm{a}^{-1}$ to emphasise the upstream extent of the observed speed-up.

\subsection{Instantaneous and dynamic adjustment following ice-shelf collapse}

The successful model prediction of change in speed in the vicinity of the grounding line (Fig. 4) demonstrates the significant and immediate effect of an abrupt change to the transmissive 'membrane' stresses acting across the grounding line on flow dynamics, highlighting the importance of explicitly including variations in the lateral transmissive stresses in model studies.

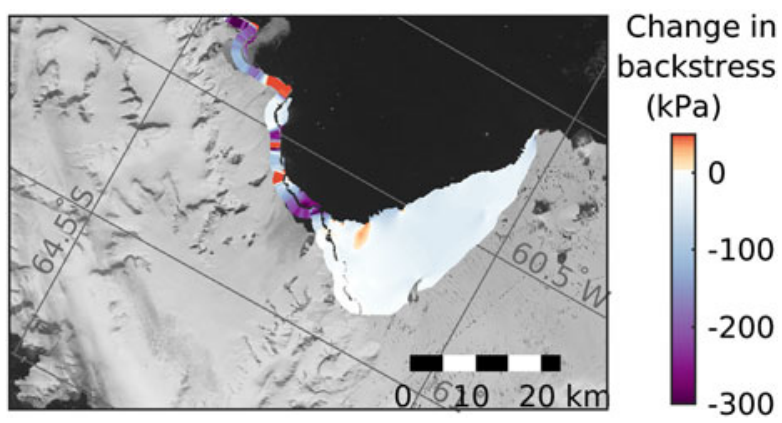

Fig. 5. The change in modelled backstress $(\mathrm{kPa})$ for Drygalski Glacier and the remnant ice shelf at Seal Nunataks as a result of the collapse of Larsen A Ice Shelf. Backstress is calculated along the grounding line (thick offset line) and within the remnant ice shelf (colouring within the ice shelf), the latter calculated with the normal vector to the grounding line replaced with the normal vector to ice flow in Gudmundsson (2013). 
While a number of modelling studies have been published that account for changes in backstress, which can propagate upstream through transmissive horizontal lateral stresses (Joughin and others, 2010; Favier and others, 2014; De Rydt and others, 2015), there are many studies that use a 'flowline' approach (Nick and others, 2009, 2012; Gladstone and others, 2012; Goelzer and others, 2013). It has been shown that flowline models are deficient in some circumstances including those more complex settings where buttressing effects are important (Gudmundsson and others, 2012; Gudmundsson, 2013). While the flowline models may be supplemented by including lateral stress gradients and some parameterization of the lateral boundaries, they do not explicitly include variations in these lateral stresses from changes in the width of a glacier or changes in backstress at the glacier front. Gagliardini and others (2010) discuss the complex behaviour of an ice-sheet ice-shelf system solving the full Stokes equations in plane flow. In that study, the lateral resistance of the ice shelf is accounted for by adding a body force in the momentum equation by a parameterisation on the flowline velocity. This provides sufficient variation to demonstrate interesting features in the model, but it obviously cannot accurately account for realworld variability in the lateral stresses. For regional studies attempting to predict future change, such as Nick and others (2013) and Barrand and others (2013), it is difficult to ensure that the flow dynamics of each of the glacier catchments modelled and their evolution in time can be replicated by such flowline models. Barrand and others (2013) discuss this issue, stating that their 'forecasts over the early decades following break-up, therefore, will be subject to errors arising from ignoring membrane stresses'.

There remains a substantial change in speed observed upstream in the glacier channel, which the model does not capture (Fig. 4). For example, the contour of $200 \mathrm{ma}^{-1}$ speed increase lies $12.1 \mathrm{~km}$ upstream of the grounding line in the observed data but only $4.6 \mathrm{~km}$ upstream in the model results. This remaining observed change in speed not predicted by the diagnostic model is likely to be due to dynamic adjustment of the glacier flow, for the reasons outlined below.

The post-collapse velocity observations were taken from a period 8 months after the ice shelf collapsed back to the ice edge position used in the model. Drygalski Glacier surface speed increased further between November 1995 and November 1999 (Rott and others, 2002) and dynamic thinning by glacier 'surging' was evident by a photographic survey conducted in October 2001 (De Angelis and Skvarca, 2003). The timescale of the observed response is shorter than the timescale between the 'fast' and 'slow' forcing branches from perturbations discussed by Williams and others (2012). Low frequency forcing or 'slow' perturbations lead to changes in flow at the grounding line and geometry that are able to propagate far upstream. High frequency forcing or 'fast' perturbations lead to a rapidly adjusted velocity but 'thickness varies little and upstream propagation occurs through the direct transmission of membrane stresses'. Using the approach of Williams and others (2012) for Drygalski Glacier assuming a length scale, $X^{*}$, of $34.15 \mathrm{~km}$, a mean thickness across the grounding line, $H^{*}$, of $264 \mathrm{~m}$ and a mean flow speed across the grounding line, $u^{*}$, of $498 \mathrm{~m} \mathrm{a}^{-1}$, the minimum decay length for 'fast' perturbations is calculated to be $12.4 \mathrm{~km}$ and the timescale for the demarcation between the two forcing branches is $10 \mathrm{a}$. Although these dimensional scaling factors are subject to estimations and hence are highly uncertain, the observational evidence of surging of Drygalski Glacier with associated elevation changes within 6 a of the ice-shelf collapse is suggestive of substantial mass redistribution occurring within a very short period following the significant dynamic change of the iceshelf collapse.

Thus, the observed change in speed may include both the dynamic effects of acceleration and thinning, whereas the model only includes the immediate (time-independent) effect of removing the buttressing provided by the ice shelf at the new ice edge. Additionally, there may have been substantial changes to the basal processes of the tributary glaciers following the ice-shelf collapse, in particular an increase in frictional heating or till deformation with increased velocity due to the release of backstress that could, in principle, cause acceleration upstream. The model in this study uses the same time-invariant distribution for the basal slipperiness $C$ derived from the post-collapse velocities for both model runs. Unfortunately there is no published elevation data coincident with the break-up of the ice shelf (i.e. in 1995) that could be used to understand whether or not any thinning occurred before the glacier collapse coinciding with an apparent speed up of the ice shelf (Bindschadler and others, 1994; Rack and others, 1999) and if not, how rapidly dynamic thinning was instigated. Therefore, we cannot further verify the model results.

A more stringent test of the model for future work would be to run a time-dependant forward-model to quantify the associated thinning and speed up of the glacier tens of kilometres upstream of the grounding line.

\subsection{Mass flux across the grounding line}

The grounding line has been defined by DInSAR measurements in February 1996 (Fig. 3; Rignot and others, 2011) together with the ice edge across the outlet of Drygalski Glacier. Using the ice thickness and velocities from the model, the ice volume flux out of Drygalski Glacier is modelled to be $0.63 \mathrm{~km}^{3} \mathrm{a}^{-1}$ before the ice-shelf collapse, increasing to $1.21 \mathrm{~km}^{3} \mathrm{a}^{-1}$ after the ice-shelf collapse. The equivalent modelled ice mass fluxes are 0.58 and 1.10 GT $\mathrm{a}^{-1}$ respectively. The modelled volume or mass flux therefore approximately doubles as a result of the removal of ice-shelf buttressing.

\section{CONCLUSIONS}

We have demonstrated the importance of ice-shelf buttressing for tributary glacier flow by replicating the observed acceleration following the collapse of Larsen A Ice Shelf. The observed change in speed following this abrupt collapse is successfully modelled in the vicinity of the grounding line where the maximum increase in speed occurred. The 2HD SSA model predicts an approximate doubling in mass flux across the grounding line, directly contributing to sea level rise, due solely to a reduction in ice-shelf buttressing. While a substantial increase in surface velocity and increase in glacier thinning has been observed in the months and years following ice-shelf collapse, this modelling study demonstrates the role of instantaneous adjustment to changes in englacial transmissive horizontal 'membrane' stresses using a real-world example. 
The instantaneous removal of the ice shelf in the model results in a notable velocity increase $10 \mathrm{~km}$ upstream, and tripling of the peak glacier surface speed in the vicinity of the grounding line. These results counter previous mathematical studies stating that the removal of ice-shelf buttressing leading to enhanced flow in grounded ice can be 'discounted as a significant influence on mechanical grounds' (Hindmarsh and Le Meur, 2001). Glacier speed up following ice-shelf collapse is a primary driver of mass-loss and hence sea level contribution for the Antarctic Peninsula. The results of this study demonstrate that real-world predictive modelling must accurately account for lateral transmissive stresses in order to correctly calculate changes in buttressing and the resulting temporal evolution of the ice sheet. A similar statement can be made for other regions dominated by marineterminating glaciers or ice sheets.

The observed response to the ice-shelf collapse extends further upstream into the Drygalski Glacier interior than our model suggests. Although detailed elevation observations are not available within the Drygalski Glacier catchment for the period immediately before and after the ice-shelf collapse, it is plausible that dynamic thinning (which is not included in this study) leading to steepening of the upstream glacier led to accelerations in the upstream glacier from an increase in the gravitational driving stress within a few months of the ice-shelf collapse. There is certainly evidence of significant elevation change within 6 a of the ice-shelf collapse (De Angelis and Skvarca, 2003; Shuman and others, 2011). It is also plausible that the basal properties of the glacier changed sufficiently during the period of ice-shelf collapse to accelerate upstream flow. Having successfully validated the model for the interplay between buttressing and ice flow, future work will need to demonstrate the ability of ice-sheet models in the much more stringent test of replicating the transient response and subsequent mass redistribution following ice-shelf collapse.

\section{ACKNOWLEDGEMENTS}

We thank Thorsten Seehaus and Matthias Braun at the University of Erlangen and Helmut Rott, Jan Wuite and others at ENVEO for providing derived surface velocity data for the region. We also thank two anonymous reviewers and Helen Fricker for their patience and comments, which greatly improved this paper. S.R. was funded through UK Natural Environment Research Council (NERC) research grant NE/K004867/1. G.H.G. was partly supported by core funding from the NERC to the British Antarctic Survey.

\section{REFERENCES}

Albrecht T and Levermann A (2014) Spontaneous ice-front retreat caused by disintegration of adjacent ice shelf in Antarctica. Earth Planet. Sci. Lett., 41(22), 8123-8129 (doi: 10.1016/j. epsl.2014.02.034)

Arndt JE and 15 others (2013) The International Bathymetric Chart of the Southern Ocean (IBCSO) Version 1.0 - a new bathymetric compilation covering circum-Antarctic waters. Geophys. Res. Lett., 40(12), 3111-3117 (doi: 10.1002/grl.50413)

Barrand NE and 11 others (2013) Computing the volume response of the Antarctic Peninsula ice sheet to warming scenarios to 2200. J. Glaciol., 59(215), 397-409 (doi: 10.3189/2013JoG12J139)

Bindschadler RA, Fahnestock MA, Skvarca P and Scambos TA (1994) Surface-velocity field of the northern Larsen Ice Shelf,
Antarctica. Ann. Glaciol., 20, 319-326 (doi: 10.3189/ $172756494794587294)$

Cook AJ and Vaughan DG (2010) Overview of areal changes of the ice shelves on the Antarctic Peninsula over the past 50 years. Cryosphere, 4, 77-98 (doi: 10.5194/tc-4-77-2010)

Cook AJ, Murray T, Luckman A, DG Vaughan and Barrand NE (2012) A new 100-m digital elevation model of the Antarctic Peninsula derived from ASTER Global DEM: methods and accuracy assessment. Earth Syst. Sci. Data, 4, 129-142 (doi: 10.5194/ essd-4-129-2012)

Cook AJ, Vaughan D, Luckman A and Murray T (2014) A new Antarctic Peninsula glacier basin inventory and observed area changes since the 1940s. Antarct. Sci., 26(6), 614-624 (doi: 10.1017/S0954102014000200)

Cooper APR (1997) Historical observations of Prince Gustav Ice Shelf. Polar Rec., 33(187), 285-294 (doi: 10.1017/S0032247400025389)

De Angelis H and Skvarca P (2003) Glacier surge after ice shelf collapse. Science, 299(5612), 1560-1562 (doi: 10.1126/science. 1077987)

De Rydt J, Gudmundsson GH, Rott H and Bamber JL (2015) Modelling the instantaneous response of glaciers after the collapse of the Larsen B Ice Shelf. Geophys. Res. Lett., 42(13), 5355-5363 (doi: 10.1002/2015GL064355)

Doake CSM, Corr HFJ, Rott H, Skvarca P and Young NW (1998) Breakup and conditions for stability of the northern Larsen Ice Shelf, Antarctica. Nature, 391, 778-780 (doi: 10.1038/35832)

Dupont TK and Alley RB (2005) Assessment of the importance of iceshelf buttressing to ice-sheet flow. J. Geophys. Res., 32, L04503 (doi: 10.1029/2004GL022024)

Favier L and 8 others (2014) Retreat of Pine Island Glacier controlled by marine ice-sheet instability. Nat. Clim. Change, 4, 117-141 (doi: 10.1038/nclimate2094)

Ferrigno JG and 8 others (2008) Coastal-change and glaciological map of the Larsen Ice Shelf area, Antarctica: 1940-2005. US Geological Survey Geological Map I-2600-B, data available to download from the Antarctic Digital Database. http://add.scar.org/.

Gagliardini O, Durand G, Zwinger T, Hindmarsh R and Meur EL (2010) Coupling of ice-shelf melting and buttressing is a key process in ice-sheets dynamics. Geophys. Res. Lett., 37(14), L14501 (doi: 10.1029/2010GL043334)

Gilbert L and 6 others (2014) REAPER product handbook for ERS altimetry reprocessed product. Technical Report REA-UGPHB-7003. ESA. https://earth.esa.int/documents/10174/1511090/ Reaper-Product-Handbook-3.1.pdf

Gladstone RM and 9 others (2012) Calibrated prediction of Pine Island Glacier retreat during the 21 st and 22 nd centuries with a coupled flowline model. Earth Planet. Sci. Lett., 333-334, 191199 (doi: 10.1016/j.epsl.2012.04.022)

Goelzer H and 8 others (2013) Sensitivity of Greenland ice sheet projections to model formulations. J. Glaciol., 59(216), 733749 (doi: 10.3189/2013JoG12J182)

Goldberg D, Pollard DM and Schoof C (2009) Grounding line movement and ice shelf buttressing in marine ice sheets. J. Geophys. Res., 114, F04026 (doi: 10.1029/2008JF001227)

Gudmundsson GH (2013) Ice-shelf buttressing and the stability of marine ice sheets. Cryosphere, 7, 647-655 (doi: 10.5194/tc-7647-2013)

Gudmundsson GH, Krug J, Durand G, Favier L and Gagliardini O (2012) The stability of grounding lines on retrograde slopes. Cryosphere, 6, 1497-1505 (doi: 10.5194/tc-6-1497-2012)

Hindmarsh RCA (1993) Qualitative dynamics of marine ice sheets. In Ice in the Climate System, volume 12 of Series 1: Global Environmental Change, Springer-Verlag, Berlin (doi: 10.1007/ 978-3-642-85016-5_5)

Hindmarsh RCA and Le Meur E (2001) Dynamical processes involved in the retreat of marine ice sheets. J. Glaciol., 47(157), 271-282 (doi: 10.3189/172756501781832269)

Huss $M$ and Farinotti D (2014) A high-resolution bedrock map for the Antarctic Peninsula. Cryosphere, 8, 1261-1273 (doi: 10.5194/tc-8-1261-2014) 
Joughin I, Smith BE and Holland DM (2010) Sensitivity of 21st century sea level to ocean-induced thinning of Pine Island Glacier, Antarctica. Geophys. Res. Lett., 37(20), L20502 (doi: 10.1029/2010GL044819)

Katz RF and Worster MG (2010) Stability of ice-sheet grounding lines. Proc. R. Soc. A, 471(2183), 1597-1620 (doi: 10.1098/ rspa.2009.0434)

Ligtenberg SRM, Helsen MM and van den Broeke MR (2011) An improved semi-empirical model for the densification of Antarctic firn. Cryosphere, 5, 809-819 (doi: 10.5194/tc-5-809-2011)

Liu H, Jezek K, Li B and Zhao Z (2001) Radarsat Antarctic mapping project digital elevation model version 2. NSIDC: National Snow and Ice Data Center, Boulder, CO (doi: 10.5067) PXKC81A7WAXD)

MacAyeal DR (1992) The basal stress distribution of Ice Stream E, Antarctica, inferred by control methods. J. Geophys. Res.: Solid Earth, 97(B1), 595-603 (doi: 10.1029/91JB02454)

MacAyeal DR (1993) A tutorial on the use of control methods in icesheet modeling. J. Glaciol., 39(131), 91-98 (doi: 10.3198/ 1993JoG39-131-91-98)

Nick FM, Vieli A, Howat IM and Joughin I (2009) Large-scale changes in Greenland outlet glacier dynamics triggered at the terminus. Nat. Geosci., 2, 110-114 (doi: 10.1038/NGEO3947)

Nick FM and 8 others (2012) The response of Petermann Glacier, Greenland, to large calving events, and its future stability in the context of atmospheric and oceanic warming. J. Glaciol., 58 (208), 229-239 (doi: 10.3189/2012JoG11J242)

Nick FM and 7 others (2013) Future sea-level rise from Greenland's main outlet glaciers in a warming climate. Nature, 497, 235-238 (doi: 10.1038/nature12068)

Padman L, Fricker HA, Coleman R, Howard S and Erofeeva S (2002) A new tidal model for the Antarctic ice shelves and seas. Ann. Glaciol., 34, 247-254 (doi: 10.3189/172756402781817752)

Pattyn F and 18 others (2012) Results of the Marine Ice Sheet Model Intercomparison Project, MISMIP. Cryosphere, 6, 573-588 (doi: 10.5194/tc-6-573-2012)

Pattyn F and 27 others (2013) Grounding-line migration in plan-view marine ice-sheet models: results of the ice2sea MISMIP3d intercomparison. J. Glaciol., 59(215), 410-422 (doi: 10.3189/2013JoG12J129)

Rack W, Rott H, Siegel A and Skvarca P (1999) The motion field of northern Larsen Ice Shelf, Antarctic Peninsula, derived from satellite imagery. Ann. Glaciol., 29, 261-266 (doi: 10.3189/ 172756499781821120)

Rignot EJ, Mouginot J and Scheuchl B (2011) Antarctic grounding line mapping from differential satellite radar interferometry. Geophys. Res. Lett., 38, L10504 (doi: 10.1029/2011GL047109)

Ritz C, Rommelaere V and Dumas C (2001) Modeling the evolution of Antarctic ice sheet over the last 420,000 years: implications for altitude changes in the Vostok region. J. Geophys. Res., 106 (D23), 31943-31964 (doi: 10.1029/2001JD900232)

Rott H, Skvarca P and Nagler T (1996) Rapid collapse of northern Larsen Ice Shelf, Antarctica. Science, 271(5250), 788-792 (doi: 10.1126/science.271.5250.788)

Rott H, Rack W, Stuefer M and Skvarca P (1997) Significant ice retreat in the region Patagonia - Antarctic Peninsula observed by ERS SAR. In 3rd ERS SYMPOSIUM Florence 97 - Abstracts and Papers, ESA. https://earth.esa.int/workshops/ers97/papers/ rott1/index-2.html

Rott H, Rack W, Skvarca P and Angelis HD (2002) Northern Larsen Ice Shelf, Antarctica: further retreat after collapse. Ann. Glaciol., 34, 277-282 (doi: 10.3189/172756402781817716)

Rott $\mathrm{H}$ and 5 others (2014) Mass changes of outlet glaciers along the Nordensjköld Coast, northern Antarctic Peninsula, based on TanDEM-X satellite measurements. Geophys. Res. Lett., 41(22), 8123-8129 (doi: 10.1002/2014GL061613)

Scambos TA, Hulbe C, Fahnestock M and Bohlander J (2000) The link between climate warming and break-up of ice shelves in the Antarctic Peninsula. J. Glaciol., 46(1542), 516-530 (doi: 10.3189/172756500781833043)

Scambos TA and 6 others (2014) Detailed ice loss pattern in the northern Antarctic Peninsula: widespread decline driven by ice front retreats. Cryosphere, 8, 2135-2145 (doi: 10.5194/tc-8-21352014)

Seehaus T, Marinsek S, Helm V, Skvarca P and Braun M (2015) Changes in ice dynamics, elevation and mass discharge of Dinsmoor-Bombardier-Edgeworth glacier system, Antarctic Peninsula. Earth Planet. Sci. Lett., 427, 125-135 (doi: 10.1016/ j.epsl.2015.06.047)

Shuman CA, Berthier E and Scambos TA (2011) 2001-2009 elevation and mass losses in the Larsen A and B embayments, Antarctic Peninsula. J. Glaciol., 57(204), 737-754 (doi: 10.3189/002214311797409811)

Skvarca P, Rack W, Rott H and Ibarzábal y Donángelo T (1999) Climatic trend and the retreat and disintegration of ice shelves on the Antarctic Peninsula: an overview. Polar Rec., 18(2), 151-157 (doi: 10.3189/172756404781814573)

Vieli A, Payne AJ, Shepherd A and Du Z (2007) Causes of pre-collapse changes of the Larsen B ice shelf: numerical modelling and assimilation of satellite observations. Earth Planet. Sci. Lett., 259(3-4), 297-306 (doi: 10.1016/j.epsl.2007.04.050)

Weertman J (1974) Stability of the junction of an ice sheet and ice shelf. J. Glaciol., 13, 3-11 (doi: 10.3198/1974JoG1367-3-11)

Williams CR, Hindmarsh RCA and Arthern RJ (2012) Frequency response of ice streams. Proc. R. Soc. A, 468, 3285-3310 (doi: 10.1098/rspa.2012.0180) 